\title{
Thermoluminescence Properties of Aluminium Oxide doped Strontium, Lithium and Germanium prepared by Combustion Synthesis method
}

\author{
Nurul Syazlin Binti Saharin ${ }^{\star}$, N.E Ahmad, H.A Tajuddin, Abdul Rahman Tamuri \\ Department of Physics, Faculty of Science, Universiti Teknologi Malaysia, 81310 UTM Johor Bahru, Johor, Malaysia.
}

\begin{abstract}
In this work, $\mathrm{Al}_{2} \mathrm{O}_{3}$ doped with $\mathrm{Sr}, \mathrm{Li}$ and $\mathrm{Ge}$ was prepared by combustion synthesis techniques for thermoluminescent (TL) ionizing radiation dosimetry applications. Dopants sample concentration were varied from $0.1 \mathrm{~mol} \%$ to $5 \mathrm{~mol} \%$ in order to study the effect of the concentration on the TL response. The optimum concentration was found to be $0.3 \mathrm{~mol} \%$ for $\mathrm{Sr}$ and $\mathrm{Li}$ and $3.0 \mathrm{~mol} \%$ for Ge. Based from the comparison of this doped material, the highest sensitivity was found for Ge doped and linear response for doses studied range of 10-80 Gy. X-Ray diffraction (XRD) patterns of the samples were recorded to confirm the formation of the sample. The sharp peaks present in the XRD confirms the sample is crystalline. The TL response of these samples for Co -60 gamma radiation were evaluated. It was observed a TL glow peak around $175^{\circ} \mathrm{C}$ for doped sample which is suitable for radiation dosimetry.
\end{abstract}

Keywords: Combustion synthesis, Aluminium oxide, Thermoluminescent dosimeter,

\section{Introduction}

One of the materials that can be considered for thermoluminescence TLD is aluminium oxide $\mathrm{Al}_{2} \mathrm{O}_{3}$, as it offers an excellent mechanical property and good mechanical stability [1]. Since the 50 's, $\mathrm{Al}_{2} \mathrm{O}_{3}$ has been used as a radiation detection and dosimetric material using thermoluminescence technique. Onother advantage properties of $\mathrm{Al}_{2} \mathrm{O}_{3}$, as linearity in wide dose range, easy handling and more reasonable price [2]. Other than that, $\mathrm{Al}_{2} \mathrm{O}_{3}$ attracted scientific interest because of its high optical, chemical and thermal stability under irradiation. The challenges were to make it sensitive to radiation [3]. Akselrod et al., (2003) reported that $\mathrm{Al}_{2} \mathrm{O}_{3}$ single crystals (sapphire, or $\alpha-\mathrm{Al}_{2} \mathrm{O}_{3}$ ) as a material for volumetric optical data storage has several fundamental advantages. Since aluminium oxide shows an effective number close to that of human tissue $\left(Z_{\mathrm{eff}}=11.28\right)$, it becomes a better choice to be used in medical and environmental dosimetry [4].

The conventional fabrication process of these dosimeters utilizes Czochralsky or Vernuil crystal growth technique, which involves the use of high temperatures $\left(>2000^{\circ} \mathrm{C}\right)$ and highly reducing atmosphere $[5,6,7]$. With the development of newer technologies, there are several other techniques to synthesize the material with low cost and easy to handle [7] such as sol-gel technique [8] on beam implantation [9], solvent evaporation [10] and combustion synthesis (CS) [5.11,12]. Among wet chemical methods, CS is an effective, and low-cost method to produce various industrially useful materials [13,14]. The solution preparation for combustion synthesis is quick and easy [15]. Furthermore, it would produce a highly pure and homogeeous powder. There are few studies done on this method, such as [16] where un-doped and Al (2-10 mol\%) doped $\mathrm{ZrO}_{2}$ nano powder were synthesized using solution combustion method having glycine as a fuel in a pre-heated sample of around $500^{\circ} \mathrm{C}$. However, the study only concerned on the optical properties of the samples and is not focused on the thermoluminescence properties. Recently, to have a better performance in the dosimetric purposes, $\mathrm{Al}_{2} \mathrm{O}_{3}$ is always doped with impurities that induce many different types of trapping centers at which charged particles would produce ionizing radiation [15]. Since then, there are a lot of efforts have been directed towards the improvements on its sensitivity via various dopants such as $\mathrm{Si}, \mathrm{Ti}$, [17], $\mathrm{Mg}$ and $\mathrm{Y}$ [18] $\mathrm{Cr}$ and $\mathrm{Ni}$ [19]. Even though studies of dopant in $\mathrm{Al}_{2} \mathrm{O}_{3}$ has been done, search for new detector material for radiation monitoring as personal dosimeter is one of the important task in TLD research.

$\overline{{ }^{*} \text { Corresponding author: syazlin3@gmail.com }}$ 
From previous study Lithium tetraborate, $\mathrm{Li}_{2} \mathrm{~B}_{4} \mathrm{O}_{7}$ (LTB) is a good tissue-equivalent material for thermoluminescent dosimetry having effective atomic number $Z_{\text {eff }}=7.25$ which closely matches with that of human tissue [20], It has also been reported that the doped LTB materials are promising quantum electronics materials [21]. LTB is a versatile insulating material with large band gap [22]. In brachytherapy, the thermoluminescence dosimetry (TLD) using LiF crystals, is an experimental method that has been extensively applied with relative source.

The strontium aluminates have attracted intense research around the world, as they offer excellent properties such as high quantum efficiency, long persistence of phosphorescence and good stability. The long-lasting phosphors (LLP) oxide materials have been developed to replace the conventional sulfide after glow materials because of their improved luminescent properties such as high initial brightness, long lasting time, suitable emission colour and satisfactory chemical stability [23]. However, thermolumiescence properties of Ge doped $\mathrm{Al}_{2} \mathrm{O}_{3}$ prepared by CS method have not been reported so far. Recently, interest of $\mathrm{Ge}$ as dopants for dosimetric purpose has increased. Based on previous study, Ge doped optical fibre as a thermoluminescence dosimeter in radiotherapy is a promising material because it gives good response an fullfill the criteria of thermoluminescence properties [24]. Due to limitation study of CS technique especially for $\mathrm{Al}_{2} \mathrm{O}_{3}$ doped with $\mathrm{Li}, \mathrm{Sr}$ and $\mathrm{Ge}$ dopants, for this present investigation, we report preliminary studies on the possibility of growing $\mathrm{Al}_{2} \mathrm{O}_{3}$ with different dopants and characterizing them for thermoluminescnet studies. We tried to explore different type of dopants such as $\mathrm{Li}, \mathrm{Sr}$ and $\mathrm{Ge}$ doped for aluminium oxide to choose the best one for future study in thermoluminescence properties prepared by CS method.

\section{Materials and Methods}

\subsection{Sample Preparation}

For preparing powder samples, stoichiometric amount of aluminium nitrate, $\left(\mathrm{Al}\left(\mathrm{NO}_{3}\right)_{3}\right)$ urea, $\left(\mathrm{CO}\left(\mathrm{NH}_{2}\right)_{2}\right)(\mathrm{Sigma}$ Aldrich reagent grade, 99.9\% pure) and dopant $\mathrm{Sr}, \mathrm{Li}$ and $\mathrm{Ge}$ were weighed using Shimadzu ATX 224 single Pan Analytical balance. The starting materials were a mixture of $15 \mathrm{~g}$ of aluminium nitrate, $\left(\mathrm{Al}\left(\mathrm{NO}_{3}\right)_{3}\right), 6 \mathrm{~g}$ of urea, $\left(\mathrm{CO}\left(\mathrm{NH}_{2}\right)_{2}\right)$ and different weight of dopant concentration from $0.1 \%$ to $5 \%$. Then, $20 \mathrm{~mL}$ distilled water was added to the sample and magnetic stirrer was used to prepare a homogeneous solution stirred for 15 minutes, for completely dissolved before transferring to alumina crucible. An alumina crucible is used as a container within which chemical reaction take place. After the solution is transferred into the crucible, it is placed into a muffle-furnace at $500^{\circ} \mathrm{C}$. Within 10 minutes, the reaction starts giving yellowish flames. The reaction was continuing for next few seconds and as it over, crucible was taken out from the furnace and kept in an open to allow cooling. Upon cooling, white foamy product formed which was then crushed using agate pestle mortar to get material in the powder form.

\subsection{Measuring instruments}

The XRD is used to confirm the crystalline nature of the as synthesized $\mathrm{Al}_{2} \mathrm{O}_{3}$ and to identify the presence of any impurity phases of different compositions from dopant material using Siemens Diffractometer D5000. The XRD machine is equipped with diffraction software with $\mathrm{CuK} \alpha$ radiation operating at $40 \mathrm{kV}, 30 \mathrm{~mA}$ with a scanning step length of $0.05^{\circ}$ for 2 second counting per step and scanning angle from $10^{\circ}$ to $90^{\circ}$ with Bragg-Brentano geometry at room temperature. Annealing process was done to removes all residual of TL signals to re-establish TL sensitivity and eliminates unstable low-temperatures glow peak before sample is exposed. $\mathrm{Al}_{2} \mathrm{O}_{3}$ powders were annealed at $400^{\circ} \mathrm{C}$ for 1 hour followed by cooling process at $80^{\circ} \mathrm{C}$ for 16 hours [25]. To evaluate the TL response, samples with different dopant at different concentration were irradiated at 50 Gy to Cobalt-60 gamma Cell Model 220 Excel at Universiti Kebangsaan Malaysia, Bangi, Malaysia. The TL response glow curve was measured using a TLD reader Harshaw Model 3500. The TL measurement was carried out at $300^{\circ} \mathrm{C}$ with heating rate of $3{ }^{\circ} \mathrm{C} \mathrm{s}^{-1}$. All reading was taken under $\mathrm{N}_{2}$ gas flow, to ensure good thermal contact between the sample and the heater-planchette, as is customary. 


\section{Results and Discussion}

3.1 X-Ray diffraction (XRD) analysis

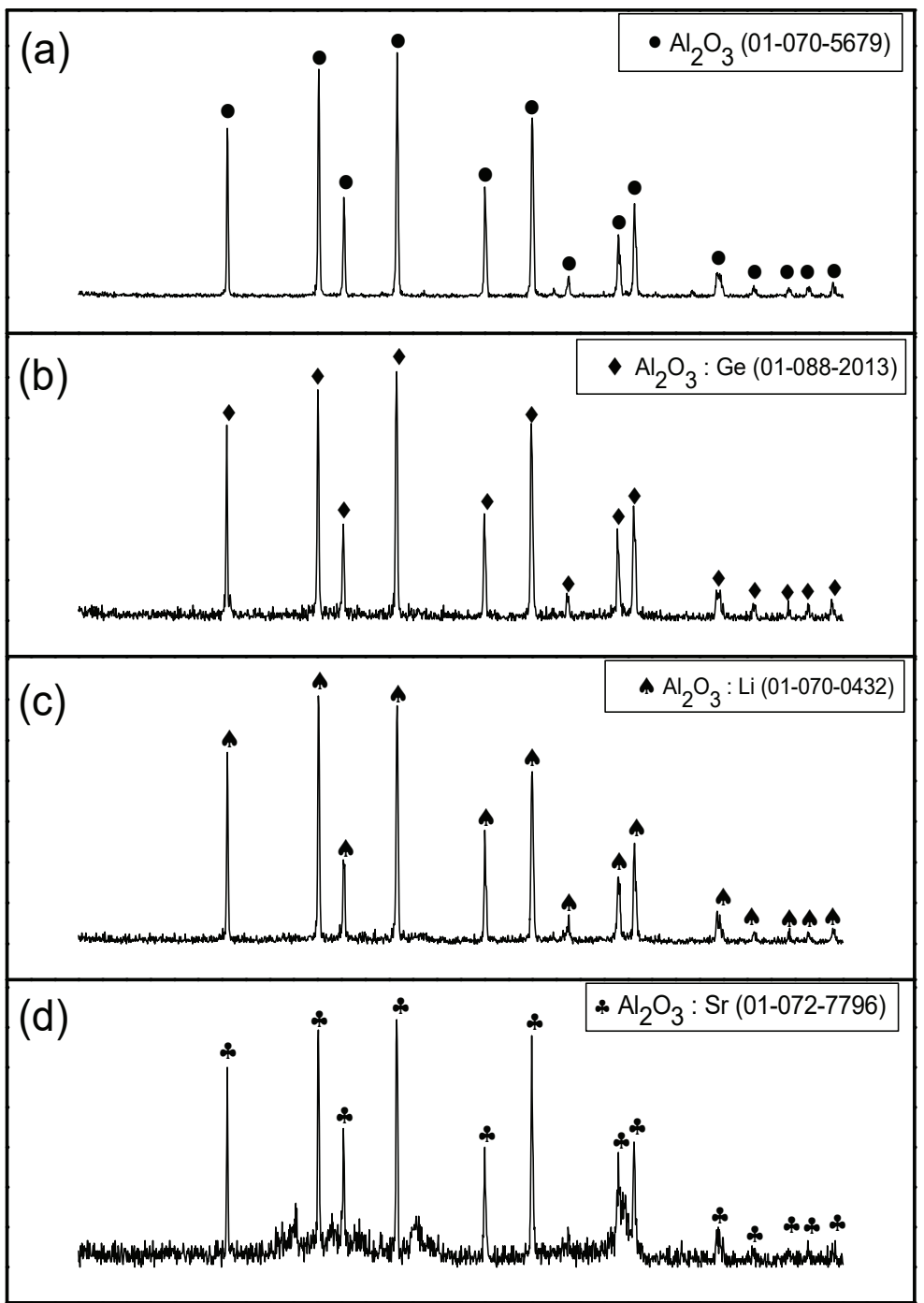

Fig 1. XRD pattern of (a) un-doped $\mathrm{Al}_{2} \mathrm{O}_{3}$, (b) $\mathrm{Al}_{2} \mathrm{O}_{3}$ doped with 3 mol\% of Ge samples,

(c) $\mathrm{Al}_{2} \mathrm{O}_{3}$ doped with $0.3 \mathrm{~mol} \%$ of Li samples, (b) $\mathrm{Al}_{2} \mathrm{O}_{3}$ doped with $0.3 \mathrm{~mol} \%$ of $\mathrm{Sr}$ samples

The XRD results prove that the prepared samples were crystalline and the respective peaks with their ICDD reference number is shown in Figure. 1 in this work. Changes of dopants do not contribute to any phase change of $\mathrm{Al}_{2} \mathrm{O}_{3}$. This finding is also supported by the previous work in [26]. They prepared $\mathrm{Al}_{2} \mathrm{O}_{3}$ by solution combustion method but using glycine as fuel.

\subsection{Determination for the optimum strontium dopant concentration}

Figure 2(a) represents the TL intensity and corresponding to standard deviation of $\mathrm{Al}_{2} \mathrm{O}_{3}$ at different $\mathrm{Sr}$ concentration. Figure 2(b) represents the glow curve of the samples at $50 \mathrm{~Gy}$ dose. From the results, the TL intensity of the sample was found to vary with decrease $\mathrm{Sr}$ concentration from $0.2 \mathrm{~mol} \%$. The intensity increases back from $0.3 \mathrm{~mol} \% 531516.04$ (a.u) and it is found to be optimum at this concentration. Based from the TL glow curve as in Figure 2 (b), the general nature of TL curves is similar in different cases: each curve peaks at temperature around $175^{\circ} \mathrm{C}$. It is observed that varying 
concentration of $\mathrm{Sr}$ does not affect the peak position much. However, the emission intensity is found to increase with increasing Sr concentration and for $\mathrm{x}=0.3 \mathrm{~mol} \%$, the intensity is quenched and decrease for further concentration. The reason for such quenching may be the increase in probability of non-radiative transitions of the luminescent molecules from the excited state to the ground state in comparison to the probability of radiative transition. No such work for $\mathrm{Al}_{2} \mathrm{O}_{3}$ : $\mathrm{Sr}$ has been reported to the best of our knowledge. From previous study this material has been considered to be effective luminescent hosts due to their low temperature synthesis, excellent chemical, physical stability and environmental stability [27]. As a conclusion, it is found that the optimum concentration value of $\mathrm{Sr}$ dopants is at $0.3 \mathrm{~mol} \%$ (535116.04) with very low standard error.
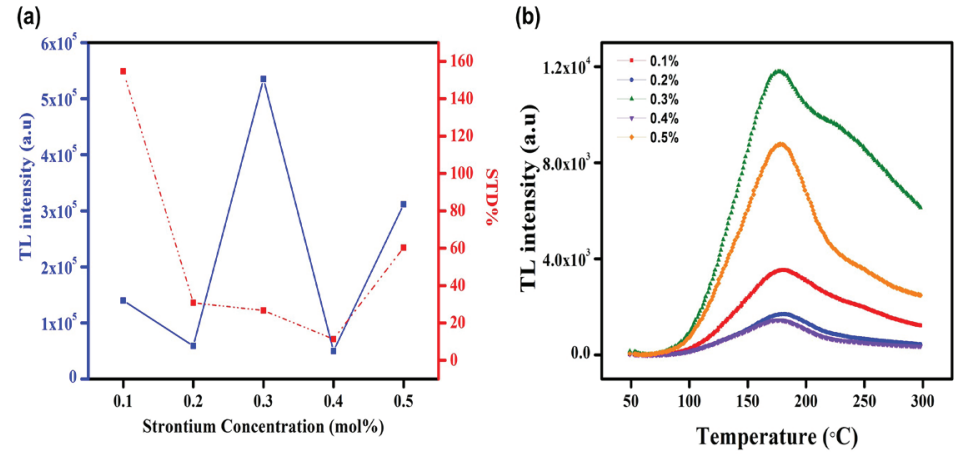

Fig 2. (a) TL intensity and correspond standard deviation as a function of different $\mathrm{Sr}$ concentration mole $(0.1$ to $0.5 \%$ mol concentration) (b) Glow curve recorded at different concentration mole (0.1 to $0.5 \%)$ of Sr dopant at a constant exposed to dose $50 \mathrm{~Gy}$

\subsection{Determination for the optimum lithium dopant concentration}

Figure 3(a) represents the TL intensity and corresponding to standard deviation of $\mathrm{Al}_{2} \mathrm{O}_{3}$ at different Li concentration. Figure3(b) represents the glow curve of the samples at 50 Gy dose. It can be seen from the Figure 3 (a) the TL intensity increase up to $0.3 \mathrm{~mol} \%$ for Li concentration 126515.14 (a.u). Then the intensity decreases with further increase of Li concentration. This may be due beyond $0.3 \mathrm{~mol} \%$ concentration, quenching is bound to occur hence the optimum concentration for Li only suite for this concentration. As conclusion, the highest TL intensity were observed for $0.3 \mathrm{~mol} \%$ of lithium concentration with (low standard error) value. The TL glow curve for $\mathrm{Al}_{2} \mathrm{O}_{3}$ : $\mathrm{Li}$ ( 0.1 to $0.5 \%$ mol concentration) was also studied. From the results, different concentration of Li playing a main role in production of TL glow curve. The prominent glow peak observed at high temperature around $175^{\circ} \mathrm{C}$. This high glow curve temperature due to high-energy traps and it is very useful for TLD phosphor characteristics [28]. No such work for $\mathrm{Al}_{2} \mathrm{O}_{3}$ : Li has been reported so far, but historically, the first basic TL material was LiF:Ti, Mg (TLD 100), whose properties are still being studied extensively. Interest of this material is due to its human tissue equivalence $\left(Z_{\mathrm{eff}}=8.04\right)$ which is an important factor for personal dosimetry, simple glow curve, high sensitivity and limited fading over a certain research.
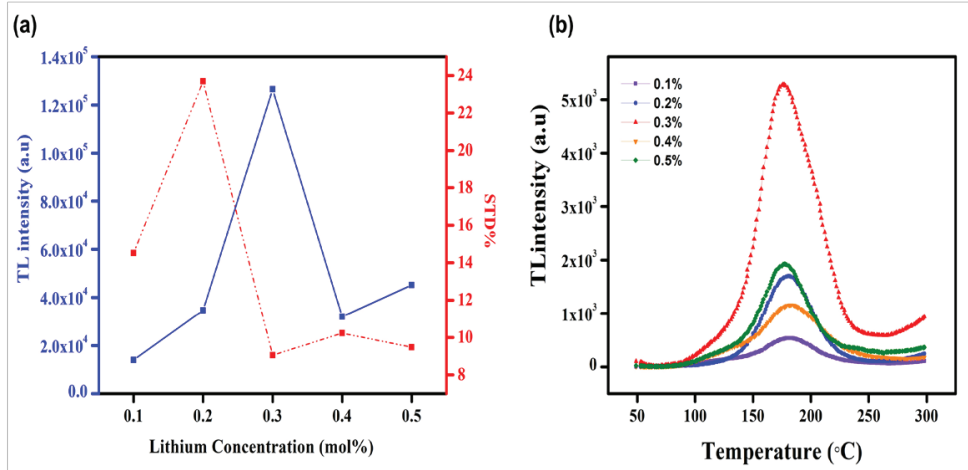

Fig 3. (a) TL intensity and correspond standard deviation as a function of different Li concentration mole (0.1 to $0.5 \%)$ (b) Glow curve recorded at different concentration mole (0.1 to $0.5 \%)$ of Li dopant at a constant exposed to dose $50 \mathrm{~Gy}$ 


\subsection{Determination for the optimum germanium dopant concentration}

Figure 4(a) represents the TL intensity and corresponding to standard deviation of $\mathrm{Al}_{2} \mathrm{O}_{3}$ at different Ge concentration. The TL intensity of the sample was found to vary with increasing Ge concentration. The TL intensity increase from $1 \mathrm{~mol} \% \mathrm{Ge}$ to maximum intensity at $3 \mathrm{~mol} \%$ Ge concentration 349747.04 (a.u). Then the intensity decreases with further increase of Ge concentration. This may be due beyond $3 \mathrm{~mol} \%$ concentration, quenching is bound to occur hence the optimum concentration for $\mathrm{Ge}$ only suite for this concentration. Highest TL intensity at $3 \mathrm{~mol} \% \mathrm{Ge}$ is attributed to the recombination of the excited electrons from the valences band with defects produced via irradiation [29]. As a conclusion, it is found that the optimum concentration value of Ge dopants is at $3 \mathrm{~mol} \%$ with very low standard error. At the same Figure 4(b) shows the glow curves $\mathrm{Al}_{2} \mathrm{O}_{3}$ : Ge samples for different concentration mole. Two peaks are observed, one prominent peak at around $175^{\circ} \mathrm{C}$ and another hump around $230^{\circ} \mathrm{C}$. It is apparent that the TL intensity of the TL peak arrive the maximum value at $0.3 \%$ mol. For further study, it is found that the optimum concentration value of Ge dopants is at $0.3 \mathrm{~mol} \%$ with very low standard error.
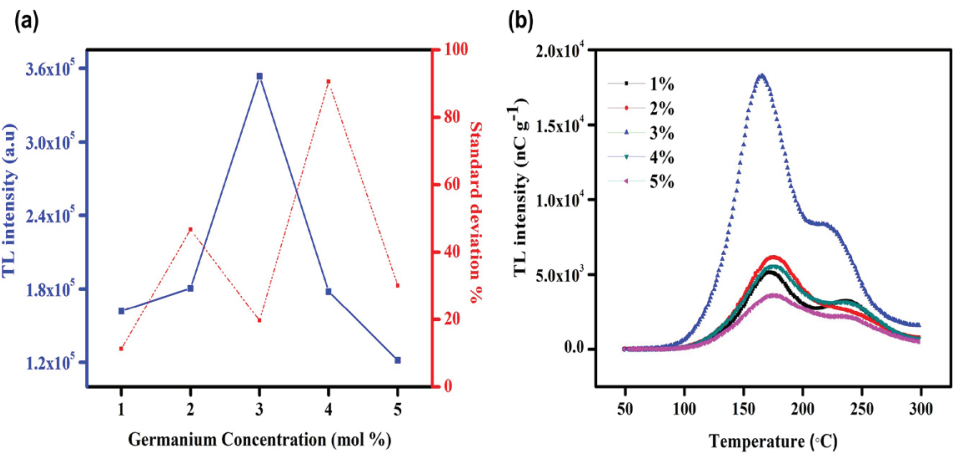

Fig 4. (a) TL intensity and correspond standard deviation as a function of different Ge concentration mole (1 to 5\%) (b) Glow curve recorded at different concentration mole (1 to 5\%) of Ge dopant at a constant exposed to dose 50Gy

\subsection{Comparison of TL glow curve for each sample}

Figure 5 represents the glow curve of materially from each optimize concentration as mention in section 3.2 to 3.5 . A very strong peak appears at $175^{\circ} \mathrm{C}$ for all samples but a small hump also appears for Ge sample at approximately $230^{\circ} \mathrm{C}$. Based from the comparison of these three dopant materials, it can be observed that $\mathrm{Al}_{2} \mathrm{O}_{3}$ doped $0.3 \%$ Germanium gives the highest TL intensity compared to other dopants which is 93 times higher. The highest TL intensity that is reflected from either the total integrated area under glow peaks or that recorded in the reading system is detected at 3.0mol\% Ge. Simple glow curve is another important property of a dosimeter. A good TLD material should display a simple glow curve and if possible has a single peak at around $200^{\circ} \mathrm{C}$ [30]. Furthermore, it should also have high resistance to environmental factor, as well as negligible dependence of its emission on radiation energy. As a conclusion for further study $\mathrm{Al}_{2} \mathrm{O}_{3}$ : $\mathrm{Ge}$ at $3.0 \mathrm{~mol} \%$ was selected to study the glow curve of germanium dopant properties.

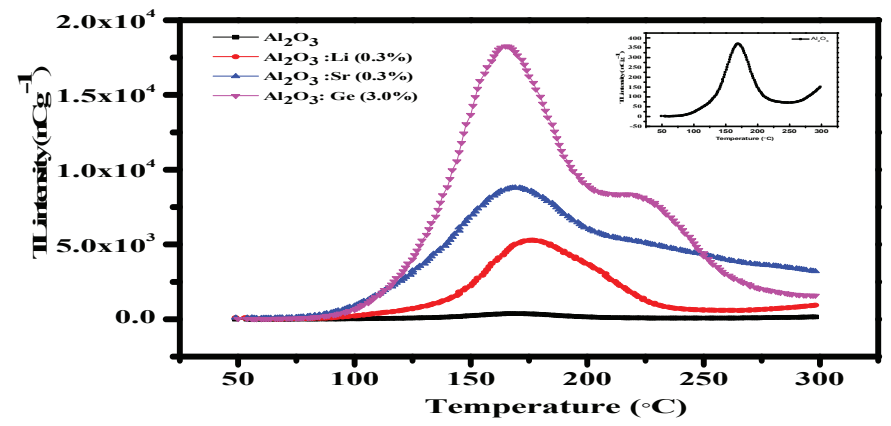

Fig 5. Glow curve recorded at different dopant material from optimum each concentration at a constant exposed to dose 50Gy 


\subsection{Glow curve analysis}

Figure 6 shows the TL glow curve of aluminium oxide doped with $3.0 \mathrm{~mol} \%$ germanium after being irradiated to Cobalt-60 gamma rays at dose ranging from $10 \mathrm{~Gy}$ to $80 \mathrm{~Gy}$. The glow curves recorded for all doses delivered the glow peak falls at around $175^{\circ} \mathrm{C}$ and $230^{\circ} \mathrm{C}$. The figure also indicates the TL intensity increase as the delivered dose increase. This results also agrees when $\alpha-\mathrm{Al}_{2} \mathrm{O}_{3}$ doped either with $\mathrm{Tb}^{3+}$ or $\mathrm{Tm}^{3+}$ was prepared by combustion synthesis techniques studied by [11]. In this method the reactants (aluminium nitrate, urea and terbium or thulium nitrate) are ignited in a muffle furnace at temperatures as low as $500^{\circ} \mathrm{C}$. The samples were annealed at temperatures ranging from 1000 to $1400^{\circ} \mathrm{C}$ for $4 \mathrm{~h}$ in order to obtain the pure $\alpha$-phase structure and were then irradiated with a Co-gamma radiation source. Tb ${ }^{3+}$ gives clearly TL peaks at around $190^{\circ} \mathrm{C}$ after sintering the sample at $1400^{\circ} \mathrm{C}$. The dose response for $0.1 \mathrm{~mol} \%$ for Tm ${ }^{3+}$ gives TL peaks around $\left(\sim 190^{\circ} \mathrm{C}\right)$ but the TL intensity increased 4 times better using $\mathrm{Tm}^{3+}$. Another work also by [31], tried to improve tld material nanoparticles for $\mathrm{Al}_{2} \mathrm{O}_{3}$ by different element like $\mathrm{Eu}, \mathrm{Tb}, \mathrm{Dy}, \mathrm{Cu}$ and $\mathrm{Ag}$ were synthesized by chemical combustion (propellent) method. The samples were exposed to $100 \mathrm{~Gy}$ of gamma-rays from a ${ }^{137} \mathrm{PCs}$ source. All the doped samples show poor TL sensitivity with two humps at around $150^{\circ} \mathrm{C}$ and $260^{\circ} \mathrm{C}$ except for Tb dopant. The glow curve for $\mathrm{Tb}$ has three major peaks; the highest is located at around $370^{\circ} \mathrm{C}$, second $230^{\circ} \mathrm{C}$ and third almost two components located at around $125^{\circ} \mathrm{C}$ and $90^{\circ} \mathrm{C}$.

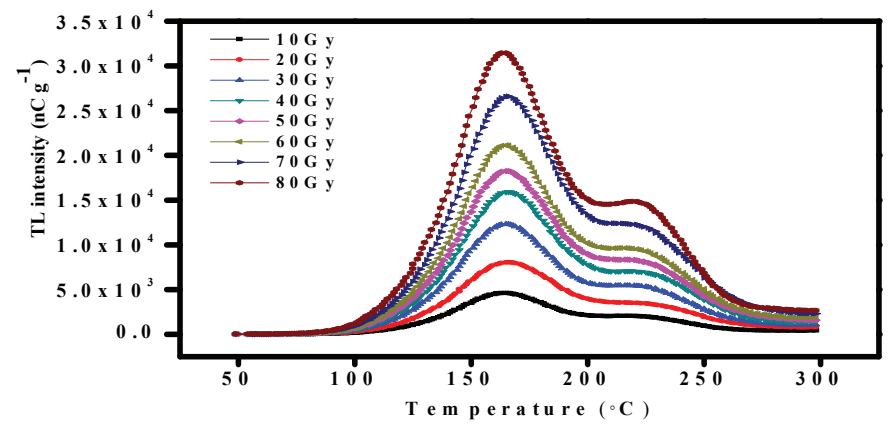

Fig.6. TL glow curve of 3.0 mol\% germanium doped aluminium oxide at different doses of Cobalt-60 gamma rays

\subsubsection{Linearity}

Linearity of dose response is one of the most crucial properties of a TL phosphor. Figure 7 indicates TL intensity versus temperature for $\mathrm{Al}_{2} \mathrm{O}_{3}$ : Ge 3\% mol exposed to Cobalt-60 Gamma Rays at various doses ranging from 10-80 Gy. The linear response indicates that the TLD is directly proportional to the dose of radiation it was irradiated with. It clearly reveals a good linear dose response with the delivered dose up to $80 \mathrm{~Gy}$. Regression coefficient $\left(\mathrm{R}^{2}\right)$ for $\mathrm{Al}_{2} \mathrm{O}_{3}$ : $\mathrm{Ge}_{3} \%$ is 0.9903. From the figure, the sensitivity of $\mathrm{Al}_{2} \mathrm{O}_{3}$ : $\mathrm{Ge} 3 \%$ is $10019 \mathrm{nCg}^{-1} \mathrm{~Gy}^{-1}$.

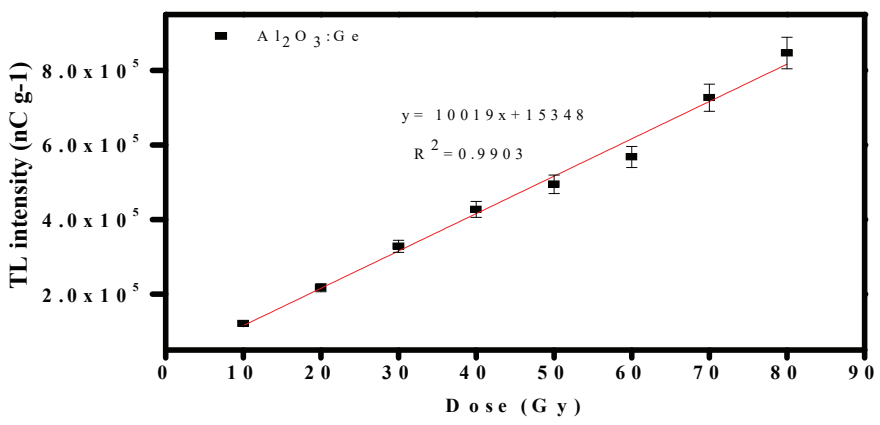

Fig7. TL intensity of $\mathrm{Al}_{2} \mathrm{O}_{3}$ : Ge $3 \%$ mol irradiated to Cobalt-60 gamma ray for doses ranging from $10 \mathrm{~Gy}$ to $80 \mathrm{~Gy}$ 


\section{Conclusion}

From the results, it is possible to conclude that the CS method is very suitable for the preparation of $\mathrm{Al}_{2} \mathrm{O}_{3}$ doped materials for dosimetric applications. This technique is quick and easy process, with as main advantages the saving time and energy. From the comparison of three doped materials, Ge, $\mathrm{Sr}$ and $\mathrm{Li}$, the concentration analysis show that the Ge concentration that optimizes the TL response $3 \mathrm{~mol} \%$ and in order to obtain well TL response peak for dosimetric applications. The crystallinity of the samples is proven by the XRD sharp peaks. The results will provide TL intensity, which depends on the delivered dose. The sensitivity found for $\mathrm{Al}_{2} \mathrm{O}_{3}: \mathrm{Ge} 3 \%$ is $10019 \mathrm{nCg}^{-1} \mathrm{~Gy}^{-1}$

\section{Acknowledgement}

The authors would like to thank the Ministry of Education (MOE) of Malaysia for the financial support (Vote Number: 10H20) and Universiti Kebangsaan Malaysia for providing irradiation source of Cobalt-60 gamma Cell Model 220 Excel and Universiti Teknologi Malaysia for providing research facilities.

\section{References}

[1] Konrad, A., Fries, T., Gahn, A., Kummer, F., Herr, U., Tidecks, R., Sammer, K., 1999. Chemical vapor synthesis and luminescence properties of nanocrystalline cubic $\mathrm{Y}_{2} \mathrm{O}_{3}$. Eur. J. Appl. Physiol. 86, 3129-3133.

[2] O. Margit., T. BIRO., Aluminium oxide in TL Dosimetry. Nucl. Instr. Meth, 175, 60-61, (1980).

[3] M.S., Akselrod, A.E., Akselrod, S.S., Orlov, S. Sanyal and T.H., Unerwood, FluorescentAluminium Oxide Crystals for Volumetric Optical Data Storage and Imaging Applications. Journal of Fluorescence.13,6. (2003).

[4] A.J. J, Bos, High sensitivity thermoluminescence dosimetry. Nucl. Inst Meth. Phys. Res. B. 184: 3-28, (2001).

[5\} D.V, Barros, S.M. de Azevedo Walter, M. Khoury and Pedro Linhares Filho, Combustion synthesis: A suitable method to prepare $\mathrm{Al}_{2} \mathrm{O}_{3}$ doped materials for thermoluminescent dosimetry. Radiat. Meas. 43, 345-348, (2008).

[6] M.E.A. Andrade, W.M. Azevedo, V.S.M Barros, and H.J Khoury, Thermoluminescence of aluminium oxide co-doped with terbium and thulium obtained via combustion synthesis. Radiat. Meas. 46, 1474-1476, (2011)

[7] J.V. Soares, C.F, Gugliotti, Y.S. Kawashima, S.H. Tatumi, J.C.R. Mittani, Thermoluminescence and optically stimulated luminescence characteristics of $\mathrm{Al}_{2} \mathrm{O}_{3}$ doped Tb. Radiat.Meas, 71, 78-80, (2014).

[8] A.A. Kaplyankii, A.B. Kulinkin, A.B. Kutsenko, S.P. Feofilov, R.I. Zakharchenya, T.N. Vasilevskaya, Optical spectra of triply-charged rare-earth ions in polycrystalline corundum. Phys. Sol. State, 40, 1310-1316, (1998).

[9] N. Can, P.D. Townsend, and D.E. Hole, Enhancement of luminescence by pulse laser annealing of ion-implanted europium in sapphire and silica. J. Appl. Phys.78, 6737-6744, (1995).

[10] J. Azorin, Preparation methods of thermoluminescent materials for dosimetric applications: An overview. Appl. Radiat. Isot. 83, 187-191, (2002).

[11] G. Hirata, N. Peres, M. Tajeda, J.A. Gonzalez-Ortega, and J. McKittrick, Luminescence study in Eu-doped aluminium oxide phosphors. Opt. Mater. 27,1311-1315, (2005).

[12]V.SM. Barros, W.M.de Azevedo, H.J. Khoury, M.E. A. Andrade, and P. Linhares Filho, Thermoluminescence study of aluminium oxide doped with terbium and thulium. Radiat. Meas. 45,435-437. (2010).

[13] B.N. Lakshminarasappa, J. R.Jayaramaiah, \& B. M. Nagabhushana, Thermoluminescence of combustion synthesized yttrium oxide. Powder Technol, 217: 7-10. (2012).

[14]A.Sharma, A.Rani, A.Singh, O. P. Modi, \& G. K. Gupta, Synthesis of alumina powder by the urea-glycine-nitrate combustion process: a mixed fuel approach to nanoscale metal oxides. Applied Nanoscience, 4(3): 315-323, (2014).

[15] R. K. Lenka, T. Mahata, P. K. Sinha, \& A. K. Tyagi, Combustion synthesis of gadolinia-doped ceria using glycine and urea fuels, J Alloys Compd, 466: 326-329. (2008).

[16] Ravichandran, A.T., Catherine, K., Pushpa, S., Ravichandran, K., Karthika, K., Nagabhushana, B.M., Mantha, S., and Swaminathan, K. Effect of Al doping on the structural and optical properties of $\mathrm{ZrO}_{2}$ nanopowders synthesized using solution combustion method. Superlattices and Microstructures.75, 533-542. (2014).

[17] 16. R. K. Lenka, T. Mahata, P. K. Sinha, \& A. K. Tyagi, Combustion synthesis of gadolinia-doped ceria using glycine and urea fuels, J Alloys Compd, 466: 326-329. (2008).

[18]M. C. Gardey Merino, G. E. Lascalea, L. M. Sánchez, P. G. Vázquez, E. D. Cabanillas, \& D. G. Lamas. Nanostructured aluminium oxide powders obtained by aspartic acid-nitrate gel-combustion routes. J Alloys Compd, 495(2):578-582. (2010). 
[19]F.O. Ogundare, S.A. Ogundele, M.L. Chithambo and M.K. Fasasi, Thermoluminescence characteristics of the main glow peak in $\alpha-\mathrm{Al}_{2} \mathrm{O}_{3}$ : $\mathrm{C}$ exposed to low environmental-like radiation doses. J.Lumin. 139, 143-148. (2013).

[20] Kar, S., Debnath, C., Verma, S., Dhamgaye, V. P., Lodha, G. S., \& Bartwal, K. S. Thermoluminescence studies on single crystal, polycrystalline and glass lithium tetraborate samples irradiated by X-rays from Indus-2. Physica B: Condensed Matter, 456, 1-4, (2015)

[21] V.T. Adamiv, Ya.V. Burak, I.V. Kityk, J. Kasperczyk, R. Smok, M. Czerwihki, Nonlinear optical properties of $\mathrm{Li}_{2} \mathrm{~B}_{4} \mathrm{O}_{7}$ single crystals doped with potassium and silver, Opt. Mater. 8 207-213, (1997)

[22] S. Kar, K.S. Bartwal, Growth optimization of $\mathrm{Li}_{2} \mathrm{~B}_{4} \mathrm{O}_{7}$ crystals and their characterization, Cryst. Growth Des. $72522-$ $2525,(2007)$

[23] D.S., Khatri, Ayush Khare, Piyush Jha., Thermoluminescence studies of $\mathrm{SrAl}_{2} \mathrm{O}_{4}$ : Eu Phosphors at different by concentrations, Chalcogenide Letters, 10, 121-129, (2013)

[24] E. Pekpak, A.Yilmaz, and G. Ozbayoglu. An Overview on Preparation and thermoluminescence Characterization of Lithium Borates for Dosimetric Use. The Open Mineral Processing Journal. 3, 14-24. (2010).

[25] F.O. Ogundare, S.A. Ogundele, M.L. Chithambo and M.K. Fasasi, Thermoluminescence characteristics of the main glow peak in $\alpha-\mathrm{Al}_{2} \mathrm{O}_{3}: \mathrm{C}$ exposed to low environmental-like radiation doses. J.Lumin. 139, 143-148. (2013).

[26] M. Farahmandjou, N. Golabiyan, Solution Combustion Preparation of Nano- $\mathrm{Al}_{2} \mathrm{O}_{3}$ : Synthesis and Characterization, Trans. Phenom. Nano Micro Scales. 3(2): 100-105. (2015)

[27] Abha H. Oza, N.S. Dhoble, K.Park and S.J.Dhoble, Synthesis and thermoluminescence characterizations of $\mathrm{Sr}_{2} \mathrm{~B}_{5} \mathrm{O}_{9} \mathrm{Cl}: \mathrm{Dy}^{3+}$ phosphor for TL dosimetry, The Journal of Biological and Chemical Luminescence,30, 768-774. (2015)

[28] S. P Puppalwar, S. J Dhoble, N. S Dhoble, \& A. Kumar, Nuclear Instruments and Methods in Physics Research B Luminescence characteristics of Li 2 NaBF 6: Cu phosphor, 274, 167-171, (2012).

[29] E. Pekpak, A.Yilmaz, and G. Ozbayoglu. An Overview on Preparation and thermoluminescence Characterization of Lithium Borates for Dosimetric Use. The Open Mineral Processing Journal. 3, 14-24. (2010).

[31] Numan Salah., Najlaa Alharbi, D., Sami Habib, S., and Lochab, S.P. Thermoluminescence properties of $\mathrm{Al}_{2} \mathrm{O}_{3}$ : Tb nanoparticles irradiated by gamma rays and $85 \mathrm{MeV} \mathrm{C}^{6+}$ ion beam. Journal Luminescence. 167,59-64. (2015). 